3. Espada R, Talwalker NG, Wilcox G, Kleiman NS, Verani MS. Visualization of ventricular fibroelastoma with a video-assisted thoracoscope. Ann Thorac Surg. 1997;63: 221-3.

doi:10.1016/j.jtcvs.2007.11.064

\section{Right atrial papillary fibroelastoma associated with atrial septal defect, persistent superior vena cava, and coronary artery disease To the Editor:}

We read with interest the article by Lauten and coworkers ${ }^{1}$ regarding the successful resection of a right atrial papillary fibroelastoma $(\mathrm{PF})$. We have additional surgical experience with this infrequent location of the neoplasm.

A 60-year-old man with a history of arterial hypertension and a transient ischemic attack underwent a transthoracic echocardiogram, which demonstrated a mass inside the right atrium (RA). Further cardiologic evaluation including transesophageal echocardiogram and complete cardiac catheterization and coronary arteriography disclosed a tumor in the RA, fenestrated atrial septal defect (ASD), persistent left superior vena cava (LSVC), and severe coronary artery disease with tight stenosis in the proximal left anterior descending coronary artery (LAD) and middle right coronary artery (RCA).The patient underwent surgery on June 6, 1998. A median sternotomy was performed. Under standard cardiopulmonary bypass, with cannulation of the aorta, both venae cavae, and the LSVC, the aorta was crossclamped. Intermittent cold blood cardioplegia was administered and the three venae cavae were snared. A right atriotomy was performed, a $2 \times 1.5-\mathrm{cm}$ gelatinous tumor attached to the muscular endocardium of the RA was completely removed, an ostium secundum type of ASD was closed with an autologous pericardial patch, and a double coronary bypass graft to the LAD and RCA was carried out. The patient had an uncomplicated surgery and recovery and was discharged home 10 days after the operation. Gross and histologic examination of the mass was typical of PF. At present, 9 years 6 months after the operation, the patient remains asymptomatic. A recent transthoracic echocardiogram showed no intracavitary masses, closure of the interatrial septum, and normal left ventricular function.

$\mathrm{PF}$ is an endocardial tumor that represents the second or third most common car- diac neoplasm, accounting for less than $10 \%$ of all primary benign heart tumors. It is most frequent in the left side of the heart and generally develops in the heart valves; however, other endocardial heart locations have also been described. Right PF arising from the nontricuspid valve or interatrial septum is extremely uncommon. We only found a few surgically treated patients. ${ }^{1-7}$ To the best of our knowledge, excision of a freewall $\mathrm{PF}$ in association with closure of an ASD and coronary artery bypass grafting has not been previously reported.

$$
\begin{array}{r}
\text { Cipriano Abad, } M D^{a} \\
\text { Pilar De la Rosa, } M D^{b} \\
\text { Department of Cardiovascular Surgery }{ }^{a} \\
\text { Department of Pathology } \\
\text { Hospital Universitario } \\
\text { de Gran Canaria Dr Negrin } \\
\text { Las Palmas de Gran Canaria, Spain }
\end{array}
$$

\section{References}

1. Lauten A, Strauch JT, Wipperman J, Walers T. A rare type of right tumor in a 66-year-old woman. J Thorac Cardiovasc Surg. 2007; 133:251-2

2. Gallas MT, Reardon MJ, Reardon PR, De Felice CA, Raizner AE, Mody DR. Papillary fibroelastoma. A right atrial presentation. Tex Heart Inst J. 1993;20:293-5.

3. Singh H, Alam M, Schwartz D, Martin JR. Right atrial papillary elastoma: an uncommon location. Echocardiography. 2004;21:273-4.

4. Hindupur S, Schwabe JL. Papillary fibroelastoma of the right atrium: an atypical presentation. A case report and review of the literature. J Cardiovasc Surg. 2005;46:589-91.

5. Gabbieri D, Rossi G, Barutti L, Corghi L, Zaca F, Sarandria D, et al. Papillary fibroelastoma of the right atrium as an unusual source of recurrent pulmonary embolism. $J$ Cardiovasc Med (Hagerstown). 2006;7:273-8.

6. Lotto A, Earl UM, Owens A. Right mass Thrombus, myxoma, or cardiac papillary fibroelastoma? J Thorac Cardiovasc Surg. 2006; 132:159-60.

7. Kim RW, Jeffery ME, Smith MJ, Wilensky R1, Woo EY, Woo YJ. Minimally invasive resection of papillary fibroelastoma in a high-risk patient. J Cardiovasc Med (Hagerstown). 2007;8:639-41.

doi:10.1016/j.jtcvs.2008.01.042

\section{The present and the future in aortic stenosis management: Are there factors that might preclude surgery? \\ To the Editor:}

I read with great interest the article by Bertrand Marcheix and associates. ${ }^{1}$ I congratu- late them for this well-designed study, but I also wish to add some brief comments. The aim was to determine the impact of less-invasive techniques for treatment of highrisk patients with aortic valve disease by using a self-expandable aortic bioprosthesis (CoreValve Inc, Paris, France) suitable for percutaneous retrograde delivery. The mean logistic EuroSCORE was $32 \%$. Of 10 patients undergoing successful implants, 2 died within 30 days and a third died later, for an overall $30 \%$ hospital mortality. Vascular complications were observed in 5 patients. Mean intensive care unit stay was 4.6 days and hospital stay was 15 days. The authors concluded that the technique is a viable alternative in selected high-risk patients.

With the aim of reducing surgical invasiveness, epidural anesthesia, maintaining an autonomic ventilation, has been suggested, ${ }^{2}$ and the outcomes of 30 consecutive patients who underwent epidural awake aortic valve surgery ( $47 \%$ female, mean age $78.1 \% \pm 8,20 \%$ multivessel coronary disease, mean Logistic-EuroScore 28.3) have been presented at the European Association for Cardio-thoracic Surgery meeting in Geneva. One patient had a redo operation. Associated surgical procedures included coronary artery bypass grafting $(17 \%)$, ascending aorta replacement $(10 \%)$, mitral valve surgery $(10 \%)$, and pulmonary vein isolation to treat atrial fibrillation. Unless emergency, no other exclusion criteria were considered. One patient died, for an operative mortality of $3 \%$, and 2 patients died during the follow-up period (natural death). All other complications occurred rarely (stroke, no cases; bowel ischemia, no cases; prolonged mechanical ventilation, 2 cases; myocardial infarction, 1 case). Median stays in the ward and the intensive care unit were 4.5 days and 1 day, respectively. Seven patients have been transferred to the ward within 3 hours after surgery and 19 patients in 12 hours or less.

The goal of aortic valve stenosis treatment is to achieve a complete regression of symptoms while offering the lowest morbidity and mortality. The main reason that percutaneous interventions are more acceptable to the patients is the simplicity. Unfortunately, interventional cardiologists and cardiac surgeons are going to rethink the management of high-risk aortic stenosis ${ }^{1,3,4}$ without a well-founded clinical program and forgetting the patients' and economic 
community interests. For instance, in the series reported by Webb and colleagues, ${ }^{4} 72 \%$ had coronary artery disease. No data describe how these patients have been managed. Furthermore, a long series of exclusion criteria precluded the percutaneous aortic valve implantation in this and other series, ${ }^{3,4}$ although the implantation of a percutaneous prosthesis is initially considered in patients with absolute surgical contraindications. Nevertheless, in the experience reported by Webb and associates, ${ }^{4}$ a patient had been successfully converted to surgery. By using epidural anesthesia, my colleagues and $\mathrm{I}^{2}$ did not add any cost, and we greatly reduced the need for intensive care unit management. On the other hand, considering that the percutaneous prostheses are sold at a cost 10 -fold higher than a standard bioprostheses, and considering the early 30-day results of percutaneous implantation, ${ }^{1,3,4}$ we maintain that surgery at the moment is to be preferred over a percutaneous approach. On the contrary, we believe that currently there are no factors that might preclude surgery for any patient. Instead of finding a way to replace surgical therapy, percutaneous approaches should be used as an adjunct to surgery, to support it in its current limitations, such as being used to replace deteriorating bioprostheses and avoiding the complications related to repeated heart dissections. ${ }^{5}$

Tomaso Bottio, MD, PhD Cardiovascular Institute University of Padua Medical School Padua, Italy

\section{References}

1. Marcheix B, Lamarche Y, Berry C, Asgar A, Laborde JC, et al. Surgical aspects of endovascular retrograde implantation of the aortic
CoreValve bioprosthesis in high-risk older patients with severe symptomatic aortic stenosis. J Thorac Cardiovasc Surg. 2007;134:1150-6.

2. Bottio T, Bisleri G, Piccoli P, Negri A, Manzato A, Muneretto C. Heart valve surgery in a very high risk population: a preliminary experience in awake patients. $J$ Heart Valve Dis. 2007;16:187-94.

3. Grube E, Schuler G, Buellesfeld L, Gerckens U, Linke A, Wenaweser P, et al. Percutaneous aortic valve replacement for severe aortic stenosis in high risk patients using the second and current third generation self expanding CoreValve prosthesis. $J$ Am Coll Cardiol. 2007;50:69-76.

4. Webb JG, Pasupati S, Humphries K, Thompson C, Altwegg L, Moss R, et al. Percutaneous transarterial aortic valve replacement in selected high-risk patients with aortic stenosis. Circulation. 2007;116:755-63.

5. Zegdi R, Khabbaz Z, Borenstein N, Fabiani JN. A repositionable valved stent for endovascular treatment of deteriorated bioprostheses. $J \mathrm{Am}$ Coll Cardiol. 2006;48:1365-8.

doi:10.1016/j.jtcvs.2007.11.063

\section{Notice of Correction}

Nia AE, Amirghotran AA. Complete occlusion of the left main coronary artery ostium in Takayasu arteritis. $J$ Thorac Cardiovasc Surg. 2008;135:695-6.

The first author's name was listed incorrectly. The correct name is Abbas Emaminia.

\section{Notice of Correction}

Maselli D, De Paulis R, Weltert L, Salica A, Scaffa R, Bellisario A, Mingiano A. A new method for artificial chordae length "tuning" in mitral valve repair: Preliminary experience. J Thorac Cardiovasc Surg. 2007;134:454-9.

The following two authors were inadvertently admitted from the author line of this article: Simona Celi, MSE, PhD, and Francesca Di Puccio, MSE, PhD. 